\title{
Disaggregated control of blood vessels over platelets in milk piglets
}

\author{
Elena $S$. Tkacheva* \\ Vologda State Dairy Farming Academy named after N.V. Vereshchagin, Vologda 160555, Russia
}

\begin{abstract}
The important element in the functioning of hemostasis in the body of a piglet is platelet aggregation activity. The degree of its severity in piglets largely controls the functional state of primary hemostasis and the severity of microcirculation in their tissues, determining the formation of many functional mechanisms. The aggregation activity of platelets in early ontogenesis significantly determines the growth and development of the animal in the future and ultimately the level of its productivity. The examination of 36 healthy piglets of milk nutrition showed a decrease in the content of peroxidation products in their blood as a result of increased activity of their antioxidant potential in plasma. This led to their weak platelet alteration, contributing to their optimal aggregation activity. In piglets during the phase of milk feeding, a gradual increase in the aggregation properties of platelets is noted, regulating blood flow in vessels of the smallest caliber.
\end{abstract}

\section{Introduction}

The important part of agriculture in many countries is currently pig farming [1]. Due to the relatively high growth rate of piglets and the fecundity of sows, modern pig farming has become a reliable source of meat and bacon in many countries, which has made this industry highly profitable. To further increase the economic efficiency of pig farming, it is necessary to obtain new knowledge on the physiology of piglets and their active implementation. It becomes clear that the study of agerelated features of hematological parameters and especially hemostasis has great prospects [2].

It is recognized that platelet aggregation activity is an important element of hemostasis in a growing piglet's body. The degree of its severity in piglets largely controls the functional state of primary hemostasis and the severity of microcirculation in their tissues [3, 4], determining the formation of many functional mechanisms, including during the phase of milk feeding. The aggregation activity of platelets in this phase significantly determines the growth and development of the animal during subsequent early ontogenesis and, ultimately, the level of its productive properties at its end [5]. At the same time, the anti-aggregation ability of platelets in milkweed piglets has not yet been sufficiently studied; the severity of platelet aggregation in vitro and in vivo has not been clarified. In this regard, the present study was planned and conducted.

The research purpose: to find out the aggregation activity of platelets in piglets during the phase of milk feeding.

\section{Materials and methods}

The study was carried out in strict accordance with the ethical principles established by the European Convention for the Protection of Vertebrates Used for Experimental and Other Scientific Purposes (adopted in Strasbourg on March 18, 1986 and confirmed in Strasbourg on June 15, 2006).

The study took 15 healthy pigs of dairy nutrition of the large white breed, which were examined and examined 4 times: on the 6th day, 10th day, 15th day and 20th day of their life.

The study included the determination of plasma lipid peroxidation activity by the content of acyl hydroperoxides, thiobarbituric acid-active products by the Agat-Med company set (Russia) and antioxidant activity of the liquid part of the blood [6].

In piglets, platelet aggregation (AP) activity was determined [7] based on a visual micromethod with ADP $\left(0.5 \times 10^{-4} \mathrm{M}\right)$, collagen (1: 2 dilution of the main suspension $)$, thrombin $(0.125 \mathrm{U} / \mathrm{ml})$, ristomycin $(0.8 \mathrm{mg} / \mathrm{ml})$ and adrenaline $\left(5.0 \times 10^{-6} \mathrm{M}\right)$ with a standardized platelet count in the test plasma of $200 \times 10^{9}$ platelets/l. The index antiaggregation activity vascular wall (IAAVW) was calculated by dividing the time of antibodies during venous congestion by the time of development of antibodies without it [7].

Intravascular platelet aggregation was determined with phase contrast [8].

The research results were processed using student's criterion (td).

*Corresponding author: ilmedv1@yandex.ru 


\section{Results}

Piglets during the milk feeding phase showed a decrease in blood levels of primary products of plasma lipid peroxidation - acyl hydroperoxides and secondary thiobarbituric acid-active compounds from $1.48 \pm 0.012$ $\mathrm{D}_{233} 1 \mathrm{ml}$ to $1.37 \pm 0.016 \mathrm{D}_{233} / 1 \mathrm{ml}$ and from $3.40 \pm 0.022$ $\mu \mathrm{mol} / 1$ to $3.24 \pm 0.018 \mu \mathrm{mol} / 1$, respectively. The revealed decrease in the peroxidation intensity was possible as a result of an increase in the activity of the antioxidant potential of their plasma from $34.5 \pm 0.16$ to $36.6 \pm 0.07 \%$.

It was found that in dairy piglets, AP gradually accelerated. The earliest was AP under the influence of collagen (table). Slightly slower AP developed under the influence of ADP, ristomycin and $\mathrm{H}_{2} \mathrm{O}_{2}$. Thrombin and adrenaline antibodies appeared even later, gradually accelerating during the phase of milk supply ( $\mathrm{p}<0.05$ ).

For piglets of milk nutrition, a tendency to growth from 6 to 20 days of IAAVW life was characteristic for all applied inductors (table). The highest IAAVW was found in the assessment of antibodies with adrenaline in view of its maximum inhibition with this inducer during venous occlusion.
A slightly lower level of IAAVW is recorded with $\mathrm{H}_{2} \mathrm{O}_{2}$ and thrombin. IAAVW with collagen (up to $1.47 \pm 0.02$ ), with ADP (up to $1.48 \pm 0.03$ ) and ristomycin (up to $1.49 \pm 0.07$ ) were also inferior to them, also experiencing a slight tendency to increase during the phase milk nutrition.

In piglets between 6 to 20 days, the number of small and large aggregates increased by 20.0 and $31.2 \%$, respectively. Moreover, the platelet content in the aggregates in the animals observed reached $7.9 \pm 0.02 \%$ at the end of the phase, against $7.2 \pm 0.05 \%$ at its beginning (table).

Thus, in healthy piglets during the phase of milk feeding, an increase in vascular disaggregation activity is noted, which is one of the mechanisms for maintaining homeostasis in these animals at this age.

In piglets between 6 to 20 days, the number of small and large aggregates increased by 20.0 and $31.2 \%$, respectively. Moreover, the platelet content in the aggregates in the animals observed reached $7.9 \pm 0.02 \%$ at the end of the phase, against $7.2 \pm 0.05 \%$ at its beginning (table).

Table 1. Platelet aggregation activity in milk piglets

\begin{tabular}{|c|c|c|c|c|}
\hline \multirow{2}{*}{$\begin{array}{l}\text { Registrated } \\
\text { parameters }\end{array}$} & \multicolumn{4}{|c|}{ Age of piglets, $n=36, M \pm m$} \\
\hline & 6 day of life & 10 day of life & 15 day of life & 20 day of life \\
\hline Aggregation platelet with ADP, $\mathrm{s}$ & $42.6 \pm 0.12$ & $41.9 \pm 0.10$ & $41.3 \pm 0.07$ & $\begin{array}{c}40.6 \pm 0.08 \\
\mathrm{p}<0.05\end{array}$ \\
\hline IAAVW with ADP & $1.45 \pm 0.07$ & $1.46 \pm 0.05$ & $1.47 \pm 0.06$ & $1.48 \pm 0.03$ \\
\hline Aggregation platelet with collagen, $\mathrm{s}$ & $32.8 \pm 0.08$ & $32.1 \pm 0.05$ & $31.2 \pm 0.10$ & $\begin{array}{c}30.1 \pm 0.07 \\
\mathrm{p}<0.05\end{array}$ \\
\hline IAAVW with collagen & $1.42 \pm 0.05$ & $1.44 \pm 0.04$ & $1.45 \pm 0.03$ & $1.47 \pm 0.02$ \\
\hline Aggregation platelet with thrombin, $s$ & $58.6 \pm 0.10$ & $57.2 \pm 0.06$ & $56.1 \pm 0.08$ & $\begin{array}{c}55.0 \pm 0.05 \\
\mathrm{p}<0.05\end{array}$ \\
\hline IAAVW with thrombin & $1.44 \pm 0.09$ & $1.45 \pm 0.08$ & $1.48 \pm 0.05$ & $1.50 \pm 0.08$ \\
\hline Aggregation platelet with ristomycin, $s$ & $46.7 \pm 0.09$ & $45.3 \pm 0.11$ & $44.2 \pm 0.07$ & $\begin{array}{c}42.3 \pm 0.04 \\
\mathrm{p}<0.05\end{array}$ \\
\hline IAAVW with ristomycin & $1.43 \pm 0.03$ & $1.45 \pm 0.06$ & $1.46 \pm 0.04$ & $1.49 \pm 0.07$ \\
\hline Aggregation platelet with $\mathrm{H}_{2} \mathrm{O}_{2}, \mathrm{~s}$ & $47.6 \pm 0.08$ & $46.4 \pm 0.10$ & $45.2 \pm 0.08$ & $\begin{array}{c}44.0 \pm 0.11 \\
\mathrm{p}<0.05\end{array}$ \\
\hline IAAVW with $\mathrm{H}_{2} \mathrm{O}_{2}$ & $1.45 \pm 0.04$ & $1.46 \pm 0.08$ & $1.48 \pm 0.05$ & $1.50 \pm 0.07$ \\
\hline Aggregation platelet with adrenaline, $s$ & $100.6 \pm 0.12$ & $98.3 \pm 0.16$ & $97.1 \pm 0.10$ & $\begin{array}{c}95.8 \pm 0.14 \\
\mathrm{p}<0.05\end{array}$ \\
\hline IAAVW with adrenaline & $1.49 \pm 0.07$ & $1.49 \pm 0.04$ & $1.51 \pm 0.05$ & $1.53 \pm 0.09$ \\
\hline Platelet count in aggregates, $\%$ & $7.2 \pm 0.05$ & $7.4 \pm 0.03$ & $7.6 \pm 0.04$ & $\begin{array}{l}7.9 \pm 0.02 \\
\mathrm{p}<0.05\end{array}$ \\
\hline $\begin{array}{l}\text { The number of small aggregates of } 2-3 \text { platelets } \\
\text { per } 100 \text { free-lying platelets }\end{array}$ & $3.0 \pm 0.05$ & $3.2 \pm 0.06$ & $\begin{array}{c}3.4 \pm 0.07 \\
\mathrm{p}<0.05\end{array}$ & $\begin{array}{c}3.6 \pm 0.06 \\
\mathrm{p}<0.01\end{array}$ \\
\hline $\begin{array}{l}\text { The number of medium and large aggregates, } 4 \text { or } \\
\text { more platelets per } 100 \text { free-lying platelets }\end{array}$ & $0.16 \pm 0.08$ & $0.17 \pm 0.05$ & $\begin{array}{l}0.19 \pm 0.07 \\
\mathrm{p}<0.05\end{array}$ & $\begin{array}{l}0.21 \pm 0.08 \\
\mathrm{p}<0.01\end{array}$ \\
\hline
\end{tabular}

Note: $p$ - the reliability of the age dynamics of indicators.

Thus, in healthy piglets during the phase of milk feeding, an increase in vascular disaggregation activity is noted, which is one of the mechanisms for maintaining homeostasis in these animals at this age.

\section{Discussion}

One of the highest priorities of modern agriculture is rightly considered to be increasing production of high- quality meat products. One of the ways to solve this problem is considered to be the development of pig production - a highly profitable industry that can produce high-quality, competitive products consumed by different segments of the population of the whole world.

In this regard, the provision of food security of any state in the current conditions is rightly associated in many respects with the increase in production of pork. This makes this industry one of the priorities in agriculture, and it is in dire need of introducing 
innovative developments for its further intensive development [8].

The phase of milk nutrition is one of the most important stages of the early ontogenesis of the piglet, which largely fixes the adaptation of the body to environmental conditions and ensures its preparation for the start of nutrition with vegetable feed [9].

In the phase of milk nutrition, the formation of all organs and systems in accordance with the genetic program of a living creature under the influence of environmental factors is very active [10]. One of the systems linking the animal's body together is the hemostatic system. It is multifunctional and through a number of mechanisms is connected with other systems, organs, which in turn affect the state of aggregation of blood [12, 13].

Inactive plasma lipid peroxidation in milk piglets causes weak platelet alteration, restraining their aggregation ability, apparently due to weakening of the synthesis of proaggregants in them, providing the proper level of microcirculation in the tissues, necessary for the body's needs in conditions of milk nutrition and preparation for the beginning of intake organism of plant food [14].

A certain increase in platelet adhesion in milkweed piglets occurs through the growth of collagen receptors glycoproteins Ia-IIa and VI on their surface, which was indirectly established by enhancing antibodies with collagen [15]. Also at this age in piglets, increased platelet adhesion occurred due to increased production of von Willebrand factor in the vessel walls and its active binding to its receptors - (GPI в) on the surface of blood platelets [16, 17].

Against the background of a slight increase in the production of physiological antiplatelet agents in the vessels, a physiological level of fixation of strong aggregation agonists - collagen and thrombin to receptors on the platelet membrane is maintained at an optimum activity of phospholipase C, phosphoinositol platelet activation pathway and phosphorylation of contractile system proteins $[18,19]$.

Under conditions of a gradual increase in the synthesis of prostacyclin and nitric oxide in vessels, the increasing effect of weak aggregation inducers - ADP and adrenaline on platelet receptors was physiologically balanced [20, 21]. Apparently, the achieved effect is based on a decrease in the density and activity of platelet glycoproteins, which function as their receptors, as well as fibrinogen receptors (GPIIb-IIIa) [22, 23]. These receptor changes were inevitably accompanied by a weakening of the activity of phospholipase $A_{2}$ in platelets of piglets, which led to the elimination of a limited amount of arachidonic acid from their phospholipids [24, 25].

The increase in blood levels of disaggregants also restrained their functional capabilities of platelet cyclooxygenase and thromboxane synthetase, which minimized the synthesis of proaggregate prostaglandins in the animals observed and inhibited platelet aggregation [26]. The found slight increase in milk feeding piglets of platelet aggregation activity was confirmed by the results of evaluation of intravascular platelet activity $[27,28]$.

This confirmed that at this age, they increased the production of aggregating substances in platelets, which was functionally balanced by vascular disaggregants in real blood flow conditions during the second phase of early ontogenesis [29, 30]. This also indicated a low expression in the blood of animals of collagen of subendothelium due to the high integrity of the endothelial layer, which ensures optimum synthetic processes in it [31, 32].

\section{Conclusion}

Platelets are a physiologically significant component of the hemostatic system in piglets. The degree of their aggregation in piglets largely controls the functional state of primary hemostasis and the severity of microcirculation in their tissues. The aggregation activity of platelets in the phase of milk nutrition significantly determines the growth and development of the animal during subsequent early ontogenesis and, ultimately, the level of its productive properties.

During the study, milk piglets showed a low activity of lipid peroxidation in the liquid part of the blood. This was accompanied by an increase in the antiplatelet activity of blood vessels, providing the necessary level of their control over the aggregation activity of platelets.

It is clear that the increase in platelet activity in piglets during the second phase of early ontogenesis, physiologically balanced by the enhanced antiaggregatory properties of blood vessels, is the basis of the physiological optimum of hemocirculation processes in small vessels, and, consequently, the sufficiency of anabolism and necessary growth.

\section{References}

1. V.I. Maksimov, S.Yu. Zavalishina, A.V. Parakhnevich, E.N. Klimova, N.A. Garbart, A.A. Zabolotnaya, Yu.I. Kovalev, T.Yu. Nikiforova, E.I. Sizoreva, Physiological Dynamics Of Microrheological Characteristics Of Erythrocytes In Piglets During The Phase Of Milk Nutrition, Res. J. of Pharmaceut., Biolog. and Chemical Sci., 9(5), 454-459 (2018)

2. E.S. Tkacheva, S.Yu. Zavalishina, Physiology of Platelet Hemostasis In Piglets During The Phase Of Newborns, Res. J. of Pharmaceut., Biolog. and Chemical Sci., 9(5), 1912-1918 (2018)

3. S.Yu. Zavalishina, Functional Properties Of Coagulation Hemostasis In Calves During The Phase Of Dairy-Vegetative Nutrition, Res. J. of Pharmaceut., Biolog. and Chemical Sci., 9(5), 784-790 (2018)

4. I.N. Medvedev, T.A Kumova, Valsartan effects on platelet activity in patients with arterial hypertension and metabolic syndrome, Russ. J. of Cardiol., 3, 66-69 (2007) 
5. G.S. Mal, N.V. Vorobyeva, A.V. Makhova, I.N. Medvedev, I.I. Fayzullina, Features Of Physical Rehabilitation After Myocardial Infarction, Res. J. of Pharmaceut., Biolog. and Chemical Sci., 9(6), 280-285 (2018)

6. Z.S. Barkagan, A.P. Momot, Diagnosis and controlled therapy of hemostatic disorders (Moscow, 2008)

7. I.N. Medvedev, A.P. Savchenko, S.Yu. Zavalishina, E.G. Krasnova, T.A. Kumova, O.V. Gamolina, I.A. Skoryatina, T.S. Fadeeva, Methodology of blood rheology assessment in various clinical situations, Russ. J. of Cardiol., 5, 42-45 (2009)

8. L.V. Korepanova, O.S. Starostina, S.D. Batanov, Blood as an indicator of the interior characteristics of crossbred animals, Zootechny, 10, 26-28 (2015)

9. S.Yu. Zavalishina, Functioning Of Mechanisms Of Hemocoagulation Restriction In Calves At Change Of Methods Of Nutrition, Res. J. of Pharmaceut., Biolog. and Chemical Sci., 9(5), 800-806 (2018)

10. S.Yu. Zavalishina, Functioning Of Platelets In Milk And Vegetable Nutrition Calves, Res. J. of Pharmaceut., Biolog. and Chemical Sci., 9(5), 943949 (2018)

11. N.V. Vorobyeva, I.N. Medvedev, Functional activity of platelets in new-born calves of blackmarked breed, Bulgar. J. of Agricult. Sci., 25(3), 570-574 (2019)

12. I.N. Medvedev, T.A. Kumova, Angiotensin II receptor inhibitors: role and place in arterial hypertension and metabolic syndrome treatment, Russ. J. of Cardiol., 5, 97-99 (2007)

13. S.Yu. Zavalishina, Functional Activity Of Plasma Hemostasis In Neonatal Calves With Iron Deficiency, Who Received Ferroglucin And Glycopin, Res. J. of Pharmaceut., Biolog. and Chemical Sci., 9(5), 1186-1191 (2018)

14. S.Yu. Zavalishina, Functional Properties of Anticoagulation And Fibrinolysis In Calves Of Plant Nutrition, Res. J. of Pharmaceut., Biolog. and Chemical Sci., 9(5), 1082-1087 (2018)

15. Ju.L. Oshurkova, I.N. Medvedev, Physiological Indicators Of Platelets In Ayrshire Calves During The Dairy Feeding Phase, Res. J. of Pharmaceut., Biolog. and Chemical Sci., 9(6), 171-176 (2018)

16. S.Yu. Zavalishina, Physiology of Vascular Hemostasis In Newborn Calves, Res. J. of Pharmaceut., Biolog. and Chemical Sci., 9(5), 1037-1044 (2018)

17. G.S. Mal, E.L. Kharitonov, N.V. Vorobyeva, A.V. Makhova, I.N. Medvedev, Functional Aspects Of Body Resistance, Res. J. of Pharmaceut., Biolog. and Chemical Sci., 9(6), 60-65 (2018)

18. N.V. Vorobyeva, I.N. Medvedev, Physiological Features Of Platelet Functioning In Calves of Holstein Breed During The Newborn, Res. J. of Pharmaceut., Biolog. and Chemical Sci., 9(6), 129-135 (2018)
19. S.Yu. Zavalishina, Functional Properties Of Hemocoagulation In Calves Of Dairy Nutrition, Res. J. of Pharmaceut., Biolog. and Chemical Sci., 9(5), 1016-1022 (2018)

20. Ju.L. Oshurkova, I.N. Medvedev, Functional Features Of Platelets In Newborn Calves Ayrshire Breed, Res. J. of Pharmaceut., Biolog. and Chemical Sci., 9(6), 313-318 (2018)

21. S.Yu. Zavalishina, Deficiency Of Iron As A Cause Of Dysfunction In Calves And Piglets, Res. J. of Pharmaceut., Biolog. and Chemical Sci., 9(5), 978-983 (2018)

22. T.I. Glagoleva, I.N. Medvedev, Physiological Features Of Anti-aggregational Control Of Blood Vessels Over The Shaped Elements Of Blood In Calves At The Onset Of Ontogenesis, Res. J. of Pharmaceut., Biolog. and Chemical Sci., 9(5), 440-447 (2018)

23. S.Yu. Zavalishina, Functional Antiaggregatory Properties Of Blood Vessels In Calves During Transition From Dairy To Plant Type Of Nutrition, Res. J. of Pharmaceut., Biolog. and Chemical Sci., 9(5),1110-1116 (2018)

24. S.Yu. Zavalishina, Physiological Features Of Vascular Hemostasis In Calves Of Dairy-Vegetative Food, Res. J. of Pharmaceut., Biolog. and Chemical Sci., 9(5), 1137-1143 (2018)

25. I.N. Medvedev, O.V. Gamolina, Lisinopril effects on platelet activity in patients with arterial hypertension and impaired glucose tolerance, Russ. J. of Cardiol., 3, 45-48 (2008)

26. S.Yu. Zavalishina, Functional Features Of Platelets In Newborn Calves With Iron Deficiency, Res. J. of Pharmaceut., Biolog. and Chemical Sci., 9(5), 1153-1158 (2018)

27. I.N. Medvedev, Physiological Response Of Platelet Activity In Young People With High Normal Blood Pressure To Regular Exercise, Res. J. of Pharmaceut., Biolog. and Chemical Sci., 9(6), 1489-1494 (2018)

28. Yu.Vatnikov, A. Rudenko, P. Rudenko, Ev. Kulikov, A. Karamyan, V. Lutsay, I. Medvedev, V. Byakhova, E. Krotova, M. Molvhanova, Immuneinflammatory concept of the pathogenesis of chronic heart failure in dogs with dilated cardiomyopathy, Veterinary World, 12(9), 1491-1498 (2019)

29. I.N. Medvedev, Physiological peculiarities of thrombocyte activity of candidates into masters of sports in athletics of preadult age, Bali Medical Journal, 8(3), 635-639 (2019) DOI: 10.15562/bmj.v8i3.1090

30. I.A. Skoryatina, I.N. Medvedev, Correction of aggregation level of basic regular blood elements in patients with hypertension and dyslipidemia receiving rosuvastatin and non-medicinal treatment, Bali Medical Journal, 8(1), 194-200 (2019) DOI: 10.15562/bmj.v8i1.648 
31. E.M. Lenchenko, Yu.A. Vatnikov, E.V. Kulikov, D.A. Lozovoy, V.A. Gavrilov, L.A. Gnezdilova, V.N. Zimina, V.I. Kuznetsov, V.V. Annikov, I.N. Medvedev, A.V. Petryaeva, T.I. Glagoleva, Aspects of Salmonellosis pathogenesis using chicken models, Bali Medical Journal, 8(1), 206-210 (2019) DOI:10.15562/bmj.v8i1.920
32. I.N. Medvedev, Physiological Effects Of Physical Stress On Platelet Hemostasis In Young Individuals With High Normal Blood Pressure And Overweight, Res. J. of Pharmaceut., Biolog. and Chemical Sci., 9(6), 1466-1471 (2018) 